\title{
T1 Signal Measurements in Pediatric Brain: Findings after Multiple Exposures to Gadobenate Dimeglumine for Imaging of Nonneurologic Disease
}

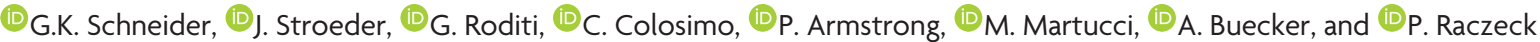

\begin{abstract}
BACKGROUND AND PURPOSE: Signal intensity increases possibly suggestive of gadolinium retention have recently been reported on unenhanced T1-weighted images of the pediatric brain following multiple exposures to gadolinium-based MR contrast agents. Our aim was to determine whether $\mathrm{Tl}$ signal changes suggestive of gadolinium deposition occur in the brains of pediatric nonneurologic patients after multiple exposures to gadobenate dimeglumine.
\end{abstract}

MATERIALS AND METHODS: Thirty-four nonneurologic patients (group 1; 17 males/17 females; mean age, 7.18 years) who received between 5 and 15 injections (mean, 7.8 injections) of $0.05 \mathrm{mmol} / \mathrm{kg}$ of gadobenate during a mean of 2.24 years were compared with 24 control patients (group 2; 16 males/8 females; mean age, 8.78 years) who had never received gadolinium-based contrast agents. Exposure to gadobenate was for diagnosis and therapy monitoring. Five blinded readers independently determined the signal intensity at ROIs in the dentate nucleus, globus pallidus, pons, and thalamus on unenhanced T1-weighted spin-echo images from both groups. Unpaired $t$ tests were used to compare signal-intensity values and dentate nucleus-pons and globus pallidus-thalamus signal-intensity ratios between groups 1 and 2 .

RESULTS: Mean signal-intensity values in the dentate nucleus, globus pallidus, pons, and thalamus of gadobenate-exposed patients ranged from 366.4 to $389.2,360.5$ to $392.9,370.5$ to 374.9 , and 356.9 to 371.0 , respectively. Corresponding values in gadolinium-based contrast agent-naïve subjects were not significantly different $(P>.05)$. Similarly, no significant differences were noted by any reader for comparisons of the dentate nucleus-pons signal-intensity ratios. One reader noted a difference in the mean globus pallidus-thalamus signal-intensity ratios $(1.06 \pm 0.006$ versus $1.02 \pm 0.009, P=.002)$, but this reflected nonsignificantly higher $\mathrm{T1}$ signal in the thalamus of control subjects. The number of exposures and the interval between the first and last exposures did not influence signal-intensity values.

CONCLUSIONS: Signal-intensity increases potentially indicative of gadolinium deposition are not seen in pediatric nonneurologic patients after multiple exposures to low-dose gadobenate.

ABBREVIATIONS: $\mathrm{DN}$ = dentate nucleus; $\mathrm{GBCA}=$ gadolinium-based contrast agent; $\mathrm{Gd}$ = gadolinium; $\mathrm{GP}$ = globus pallidus; $\mathrm{NSF}=$ nephrogenic systemic fibrosis; $\mathrm{SI}=$ signal intensity

$\mathbf{R}_{t}^{\mathrm{e}}$ ecent reports have detailed high signal intensity (SI) in certain brain areas (primarily the dentate nucleus $[\mathrm{DN}]$ and globus pallidus [GP]) on unenhanced T1-weighted images following multiple exposures to gadolinium-based contrast agents

Received January 6, 2017; accepted after revision April 24.

From the Department of Diagnostic and Interventional Radiology (G.K.S., J.S., A.B., P.R.), Saarland University Medical Center, Homburg/Saar, Germany; Department of Radiology (G.R., P.A.), National Health Service Greater Glasgow and Clyde, Glasgow Royal Infirmary, Glasgow, Scotland, UK; and Institute of Radiology (C.C., M.M.), Radiodiagnostica e Neuroradiologia, Fondazione Policlinico Universitario 'A. Gemelli', Università Cattolica del Sacro Cuore, Rome, Italy.

Please address correspondence to Guenther Schneider, MD, PhD, Department of Diagnostic and Interventional Radiology, Saarland University Medical

Center, Kirrberger Str 1, 66421 Homburg/Saar, Germany; e-mail:

dr.guenther.schneider@uniklinikum-saarland.de

http://dx.doi.org/10.3174/ajnr.A5270
(GBCAs). ${ }^{1-20}$ Many of these reports have focused on apparent differences between macrocyclic and open-chain "linear" GBCAs, ${ }^{4-13}$ invariably associating progressive T1 hyperintensity with multiple exposures to linear GBCAs and concluding that observed T1 signal reflects the lower stability of these agents and thus a greater propensity for gadolinium (Gd) release and, subsequently, deposition in the brain. Among the more recent reports are several that describe retrospective assessments in pediatric patients. ${ }^{15-19}$ Although each patient evaluated received just 1 specific linear GBCA (gadopentetate dimeglumine; Magnevist; Bayer HealthCare, Wayne, New Jersey), the study-based recommendations in each case were to consider carefully the use of all linear agents in pediatric subjects.

Gadobenate dimeglumine (MultiHance; Bracco Diagnostics, Monroe, New Jersey) is an ionic open-chain, linear GBCA that 
differs fundamentally from gadopentetate and other extracellular GBCAs in having an aromatic substituent on the chelating molecule. ${ }^{21}$ Unique properties conferred by this substituent include increased R1-relaxivity, ${ }^{22}$ which permits the acquisition of diagnostically valid images with a reduced dose, ${ }^{23}$ and liver-specificity, which permits gadobenate use for hepatobiliary-phase liver applications. ${ }^{24}$ An additional benefit is increased molecular stability compared with gadopentetate, other linear agents, and certain macrocyclic agents. ${ }^{25}$ Studies that have evaluated brain T1 signal intensities after multiple exposures to gadobenate have yielded conflicting results with one report demonstrating T1 signal increases, albeit to a lesser extent than with gadopentetate, ${ }^{10}$ and others demonstrating no direct changes. ${ }^{11,12}$

We aimed to determine whether multiple exposures to lowdose gadobenate for nonneurologic pathology results in T1 signal changes in the DN and GP of pediatric patients relative to that in age- and weight-matched GBCA-naïve control subjects.

\section{MATERIALS AND METHODS \\ Participants}

This single-center (Saarland University Medical Center, Homburg/Saar, Germany) prospective study was approved by the institutional review board. Written informed consent for the use of imaging data was obtained routinely from all parents or legal guardians at the time of the first examination. Pediatric (younger than 18 years of age), mainly oncologic patients referred for diagnosis and subsequent therapy monitoring who had undergone at least $5 \mathrm{MR}$ imaging examinations enhanced solely with gadobenate and who had no known neurologic disease or symptoms were identified from our electronic data base. Initial exposure to the first patient meeting these criteria was in August 2008. Patients with unsatisfactory images because of motion artifacts, an unknown history of GBCA administration, or severely impaired renal function (glomerular filtration rate $<30 \mathrm{~mL} / \mathrm{min}$ ) were excluded. All eligible patients underwent unenhanced T1weighted imaging of the brain as a prospective adjunctive acquisition immediately before the next scheduled routine follow-up examination (performed in all cases between September 2015 and March 2016). Thirty-four patients met the inclusion criteria (group 1). A further 24 age- and weight-matched subjects with no known neurologic disease or symptoms who had never been administered any GBCA composed a GBCA-naïve control group (group 2). Patients in group 1 received $5(n=9), 6(n=7), 7(n=$ 3), $8(n=4), 9(n=2), 10(n=3), 11(n=1), 12(n=2), 13(n=$ $1), 14(n=1)$, and $15(n=1)$ injections of gadobenate each at a dose of $0.05 \mathrm{mmol} / \mathrm{kg}$ of body weight $(0.1 \mathrm{~mL} / \mathrm{kg}$ of body weight).

\section{Imaging Protocol}

All brain MR imaging examinations were performed on 1.5T whole-body MR imaging systems (Magnetom Aera or Magnetom Symphony, Siemens, Erlangen, Germany). All examinations used an unenhanced axial T1-weighted spin-echo sequence (TR/TE, 450-650/7-12 ms; section thickness, $5 \mathrm{~mm}$ with a 1.5-mm gap). Unenhanced axial T2-weighted images were acquired with TR/ TE, 4000-5400/80-100 ms; section thickness, 5 mm; FOV, 230 $\mathrm{mm})$.

\section{Data Collection}

Four general consultant radiologists (A.B., P.R., G.R., and P.A., with $25,4,20$, and 3 years' experience, respectively) and 2 neuroradiologists in consensus (C.C., M.M., with 35 and 5 years' experience, respectively; considered reader 5), who were all blinded to patient diagnoses and details of all contrast administrations, determined SI values in operator-defined oval ROIs positioned within the DN, GP, thalamus, and pons of all patients and control subjects, as described by Kanda et al. ${ }^{1}$ Each reader was instructed to make ROIs as large as possible (mean size, $10 \mathrm{~mm}^{2}$; range, 6-18 $\mathrm{mm}^{2}$ ). ROIs in the DN were placed on the right side whenever possible and were positioned as far as possible from pulsating vessels (if present), without including rim aspects. ROIs in the GP were placed in the capsula interna; ROIs in the central pons and thalamus were adjusted as appropriate to ensure homogeneity. If T1-weighted images were considered inconclusive for visualization, T2-weighted images were available to each reader for correlation, with ROIs then placed on the corresponding T1-weighted image.

Image sets for gadobenate-exposed and GBCA-naïve subjects were randomized, transcribed to a CD-ROM, and sent by mail to each blinded reader for viewing and independent evaluation on each reader's personal PACS workstation.

\section{Statistical Analysis}

Comparison of demographic characteristics between groups 1 and 2 was performed by using a Student $t$ test for age and weight and a Fisher exact test for sex. The primary outcome measure was whether repeat exposure to gadobenate (group 1) resulted in statistically significant increases in brain intraparenchymal SI relative to that in age- and weight-matched GBCA-naïve control subjects (group 2). To evaluate the primary outcome measure, we calculated DN-pons and GP-thalamus SI ratios for all subjects. SI values determined in the DN, GP, thalamus, and pons as well as DN-pons and GP-thalamus SI ratios were compared between groups 1 and 2 with unpaired $t$ tests. Differences were considered significant for $P<.05$. Generalized multivariate linear regression was used to determine whether SI ratios were influenced by the number of gadobenate injections (control group considered as zero injections), age, sex, or weight. The interreader reliability of SI measurements was determined from the intraclass correlation coefficient, obtained from the generalized random effects regression model.

\section{RESULTS}

Demographic details of patients in groups 1 and 2 are presented in Table 1. The gadobenate-exposed subjects included 6 infants (2 years of age or younger at first exposure), 11 subjects from 2 to 8 years of age at first exposure, and 17 subjects 9 years of age or older at first exposure. No significant differences were noted for age, weight, or sex distribution between groups 1 and 2. Each patient in group 1 was administered MultiHance at a dose of 0.05 $\mathrm{mmol} / \mathrm{kg}$ of body weight. Given that $1 \mathrm{~mL}$ of MultiHance solution for injection contains $334 \mathrm{mg}$ of gadobenate, ${ }^{26}$ this corresponds to $33.4 \mathrm{mg}$ of gadobenate/ $\mathrm{kg}$ of body weight. On the basis of patient weight at each examination, a mean total accumulated dose of $9.8 \pm 8.33 \mathrm{~g}$ of gadobenate (range, 1.67-37.41 g) was adminis- 
Table 1: Summary of group characteristics ${ }^{\mathrm{a}}$

\begin{tabular}{|c|c|c|c|}
\hline Characteristic & $\begin{array}{l}\text { Gadobenate-Exposed } \\
\qquad(n=34)\end{array}$ & $\begin{array}{l}\text { GBCA-Naïve } \\
\text { Control }(n=24)\end{array}$ & $P$ Value \\
\hline Age & $\begin{array}{l}7.18 \pm 5.93 \mathrm{yr} \\
9 \mathrm{mo} \text { to } 17 \mathrm{yr}\end{array}$ & $\begin{array}{l}8.78 \pm 5.78 \mathrm{yr} \\
7 \mathrm{mo} \text { to } 17 \mathrm{yr}\end{array}$ & .31 \\
\hline $\operatorname{Sex}(M / F)$ & $17: 17$ & $16: 8$ & .28 \\
\hline Body weight $(\mathrm{kg})$ & $\begin{array}{c}30.55 \pm 18.57 \\
7.8-68\end{array}$ & $\begin{array}{c}26.71 \pm 17.23 \\
8.1-64\end{array}$ & .43 \\
\hline No. of administrations & $\begin{array}{c}7.8 \pm 2.9 \\
5-15\end{array}$ & NA & NA \\
\hline $\begin{array}{l}\text { Interval between first and last } \\
\text { administrations }\end{array}$ & $\begin{array}{l}2.24 \pm 1.97 \mathrm{yr} \\
9 \mathrm{mo} \text { to } 7 \mathrm{yr}\end{array}$ & NA & NA \\
\hline $\begin{array}{l}\text { Accumulated volume of gadobenate } \\
\text { administered }(\mathrm{mL})\end{array}$ & $\begin{array}{c}29.35 \pm 24.95 \\
5-112\end{array}$ & NA & NA \\
\hline Accumulated gadobenate dose $(g)^{b}$ & $\begin{array}{l}9.8 \pm 8.33 \\
1.67-37.41\end{array}$ & NA & NA \\
\hline
\end{tabular}

Note:-NA indicates not applicable

${ }^{\text {a }}$ Data are mean \pm SD and range.

${ }^{b}$ One milliliter of MultiHance solution for injection contains $334 \mathrm{mg}$ of gadobenic acid as the meglumine salt. ${ }^{39}$

Table 2: Summary of patient diagnoses ${ }^{a}$

\begin{tabular}{|c|c|c|c|}
\hline \multicolumn{2}{|l|}{ Group 1 (Gadobenate-Exposed) } & \multicolumn{2}{|l|}{ Group 2 (GBCA-Naïve Controls) } \\
\hline Diagnosis & No. & Diagnosis & No. \\
\hline T-cell non-Hodgkin lymphoma & 1 & Chronic recurrent osteomyelitis & 3 \\
\hline Hodgkin lymphoma & 3 & Pelvic trauma & 1 \\
\hline Coccygeal teratoma & 1 & Cystic fibrosis & 2 \\
\hline Nephroblastoma & 4 & DORV/VSD & 1 \\
\hline Neuroblastoma & 3 & Polycystic kidney disease & 1 \\
\hline Chronic recurrent osteomyelitis & 2 & Melanoma & 1 \\
\hline Hepatoblastoma & 2 & Non-Hodgkin lymphoma & 2 \\
\hline Mesoblastic nephroma & 1 & Skull base osteoid osteoma & 1 \\
\hline ALL & 1 & Germ cell tumor & 1 \\
\hline Paravertebral schwannoma & 1 & Polytrauma, knee distortion, $\mathrm{ACL}$ rupture & 1 \\
\hline Angioma of the spleen & 1 & Myocarditis & 2 \\
\hline Germ cell tumor & 2 & Hemophilia A & 1 \\
\hline Renal clear cell sarcoma & 1 & Blunt head trauma & 2 \\
\hline Ewing sarcoma & 3 & Osler disease & 1 \\
\hline Osteosarcoma & 2 & Multiple osteochondroma, whole-body staging & 1 \\
\hline Rhabdoid tumor of the kidney & 1 & $\begin{array}{l}\text { Congenital aortic malformation, whole-body } \\
\text { imaging }\end{array}$ & 1 \\
\hline Dermatofibrosarcoma & 1 & $\begin{array}{l}\text { Persistent left superior vena cava, thoracic and } \\
\text { head/neck imaging }\end{array}$ & 1 \\
\hline ARVD/ARVC & 1 & Hypertension work-up & 1 \\
\hline Hemangioendothelioma & 1 & & \\
\hline Renal leiomyosarcoma & 1 & & \\
\hline Focal nodular hyperplasia & 1 & & \\
\hline
\end{tabular}

Note:-ALL indicates acute lymphoblastic leukemia; DORV, double outlet right ventricle; VSD, ventricula septal defect; $\mathrm{ACL}$, anterior cruciate ligament; ARVD, arrhythmogenic right ventricular dysplasia; ARVC, arrhythmogenic right ventricular cardiomyopathy.

a Patients in group 1 underwent multiple gadobenate-enhanced MR imaging studies for therapy follow-up or remission control. Patients in group 2 underwent preliminary unenhanced imaging as part of the initial work-up at the first visit.

part to nonsignificantly higher mean $\mathrm{T} 1$ signal intensity in the thalamus of control subjects. Generalized multivariate linear regression confirmed no influence of the number of gadobenate exposures on SI ratios across readers after adjusting for age, sex, and weight. Strong agreement among all readers was noted for SI assessments in the DN, GP, pons, and thalamus with intraclass correlation coefficient values ranging from 0.84 to 0.97 for gadobenate-exposed subjects and from 0.86 to 0.92 for GBCA-naïve control subjects.

Figures 1 and 2 show representative T1- and T2-weighted images of pediatric brain regions after multiple injections of $0.05 \mathrm{mmol} / \mathrm{kg}$ of gadobenate in patients younger than 2 years of age ( 8 injections; total, 3.34 g of gadobenate) and $\sim 7$ years of age (14 injections; total, $27.39 \mathrm{~g}$ of gadobenate), respectively.

\section{DISCUSSION}

To date, no clinical signs or symptoms associated with $\mathrm{T} 1$ signal increases in the brain have been reported and no consequences for patient health, including neurologic function, have been identified. Nevertheless, the latest version of the American College of Radiology Manual on Contrast Media ${ }^{27}$ recommends careful consideration of the clinical benefit versus the unknown potential risk of $\mathrm{Gd}$ deposition when deciding to perform a Gd-enhanced MR imaging study and particular attention paid to pediatric and other patients who may receive many GBCA-enhanced MR imaging studies during their lifetime. It further recommends taking into account multiple factors when selecting a GBCA, including diagnostic efficacy, relaxivity, rate of adverse reactions, dosing/con-

tered per patient at a mean volume of $3.85 \pm 3.14 \mathrm{~mL} /$ examination (1.27 \pm 1.05 g gadobenate/examination). Patient diagnoses and reasons for follow-up imaging of patients in group 1 are given in Table 2 .

SI values determined in the DN, GP, pons, and thalamus as well as the DN-pons and GP-thalamus SI ratios are reported in Table 3. No significant differences $(P>.05)$ in T1 signal intensity between gadobenate-exposed and GBCA-naïve control subjects were noted in any brain region by any reader. Similarly, no significant differences between gadobenate-exposed and GBCA-naïve control subjects were noted by any reader for DN-pons SI ratios. A significant difference in GP-thalamus SI ratios was noted by 1 of 5 readers (reader 5), but this was considered anomalous due in centration, and propensity to deposit in more sensitive organs such as the brain. Our findings in 34 nonneurologic pediatric patients who received between 5 and 15 administrations of lowdose $(0.05 \mathrm{mmol} / \mathrm{kg}$ of body weight $)$ gadobenate revealed no differences in T1 signal intensity in the DN, GP, pons, and thalamus relative to the SI measurements in 24 age- and weight-matched control subjects who had never been exposed to GBCA. Likewise, no significant differences in DN-pons SI ratios were noted, while just 1 of 5 blinded readers reported a significantly higher GPthalamus SI ratio, which could be ascribed to higher T1 signal intensity in the thalamus of control subjects.

Our findings are in contrast to those of Flood et al, ${ }^{18}$ who found an increased DN-pons SI ratio in patients exposed to gado- 
Table 3: Comparison of brain SI values and DN-pons and GP-thalamus SI ratios between gadobenate-exposed and GBCA-naïve control subjects $^{\mathrm{a}}$

\begin{tabular}{|c|c|c|c|c|c|c|}
\hline Reader/Patient Group & DN & Pons & GP & Thalamus & DN-Pons Ratio & GP-Thalamus Ratio \\
\hline \multicolumn{7}{|l|}{ Reader 1} \\
\hline Exposed & $366.4 \pm 8.62$ & $370.5 \pm 8.59$ & $360.5 \pm 10.2$ & $360.3 \pm 9.99$ & $0.989 \pm 0.004$ & $1.0 \pm 0.003$ \\
\hline Control & $374.3 \pm 8.12$ & $377.0 \pm 8.65$ & $364.4 \pm 10.3$ & $363.2 \pm 9.88$ & $0.994 \pm 0.004$ & $1.0 \pm 0.002$ \\
\hline$P$ value & .526 & .609 & 0.796 & .842 & .383 & .572 \\
\hline \multicolumn{7}{|l|}{ Reader 2} \\
\hline Exposed & $367.8 \pm 9.33$ & $373.6 \pm 8.84$ & $392.3 \pm 11.17$ & $370.5 \pm 10.66$ & $0.984 \pm 0.006$ & $1.06 \pm 0.009$ \\
\hline Control & $370.9 \pm 9.70$ & $381.9 \pm 10.25$ & $380.5 \pm 11.59$ & $373.3 \pm 11.1$ & $0.972 \pm 0.007$ & $1.02 \pm 0.009$ \\
\hline$P$ value & .826 & .547 & .476 & .859 & .217 & .185 \\
\hline \multicolumn{7}{|l|}{ Reader 3} \\
\hline Exposed & $389.2 \pm 9.79$ & $374.5 \pm 8.63$ & $383.6 \pm 10.68$ & $356.9 \pm 9.06$ & $1.04 \pm 0.009$ & $1.07 \pm 0.012$ \\
\hline Control & $386.3 \pm 10.14$ & $380.9 \pm 10.73$ & $383.5 \pm 12.98$ & $365.6 \pm 11.67$ & $1.02 \pm 0.009$ & $1.05 \pm 0.011$ \\
\hline$P$ value & .839 & .642 & .996 & .555 & .101 & .134 \\
\hline \multicolumn{7}{|l|}{ Reader 4} \\
\hline Exposed & $365.3 \pm 8.40$ & $372.6 \pm 8.71$ & $381.1 \pm 9.95$ & $369.9 \pm 9.54$ & $0.98 \pm 0.006$ & $1.03 \pm 0.006$ \\
\hline Control & $368.3 \pm 9.47$ & $378.5 \pm 10.28$ & $381.8 \pm 10.57$ & $376.3 \pm 9.28$ & $0.97 \pm 0.005$ & $1.01 \pm 0.007$ \\
\hline$P$ value & .816 & .661 & .959 & .644 & .388 & .083 \\
\hline \multicolumn{7}{|l|}{ Reader 5} \\
\hline Exposed & $386.5 \pm 9.82$ & $374.9 \pm 9.04$ & $392.9 \pm 10.64$ & $371.0 \pm 9.68$ & $1.03 \pm 0.013$ & $1.06 \pm 0.006$ \\
\hline Control & $386.3 \pm 10.85$ & $383.4 \pm 10.71$ & $385.4 \pm 12.47$ & $376.8 \pm 11.17$ & $1.01 \pm 0.007$ & $1.02 \pm 0.009$ \\
\hline$P$ value & .987 & .547 & .647 & .699 & .147 & .002 \\
\hline
\end{tabular}

${ }^{a}$ Values are mean \pm standard error of the mean.
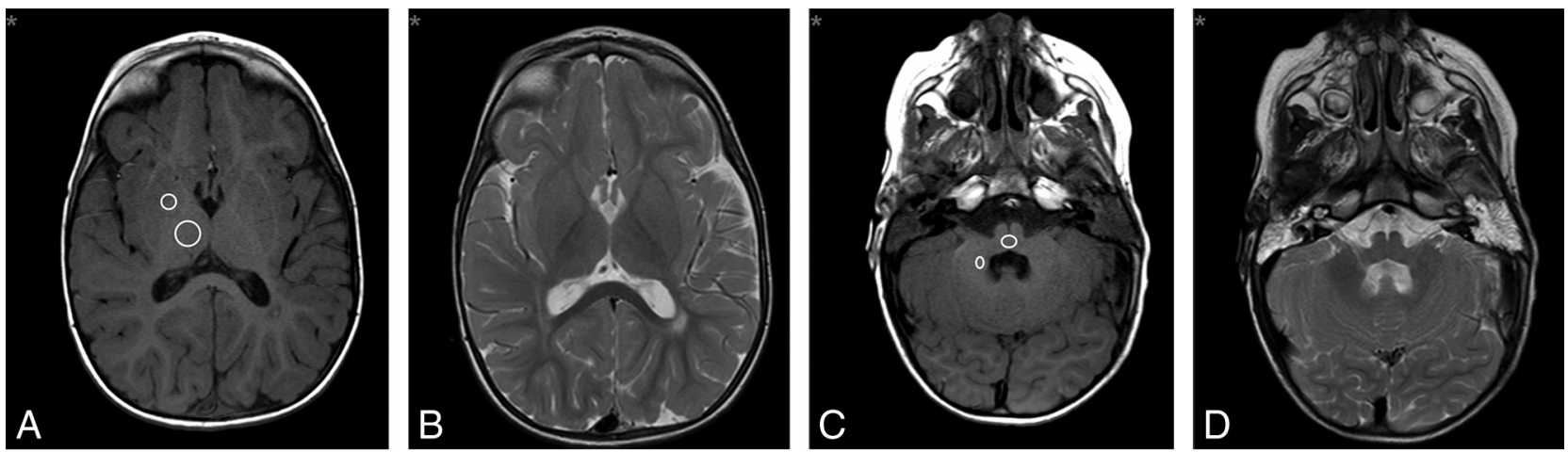

FIG 1. Oncologic male patient (1 year 9 months of age at his first visit) undergoing follow-up imaging for cervical neuroblastoma in remission. Unenhanced T1- and T2-weighted transverse images of the DN-pons ( $A$ and $B$ ) and GP-thalamus $(C$ and $D)$ after 8 injections of $0.05 \mathrm{mmol} / \mathrm{kg}$ of gadobenate reveal no evidence of SI changes.
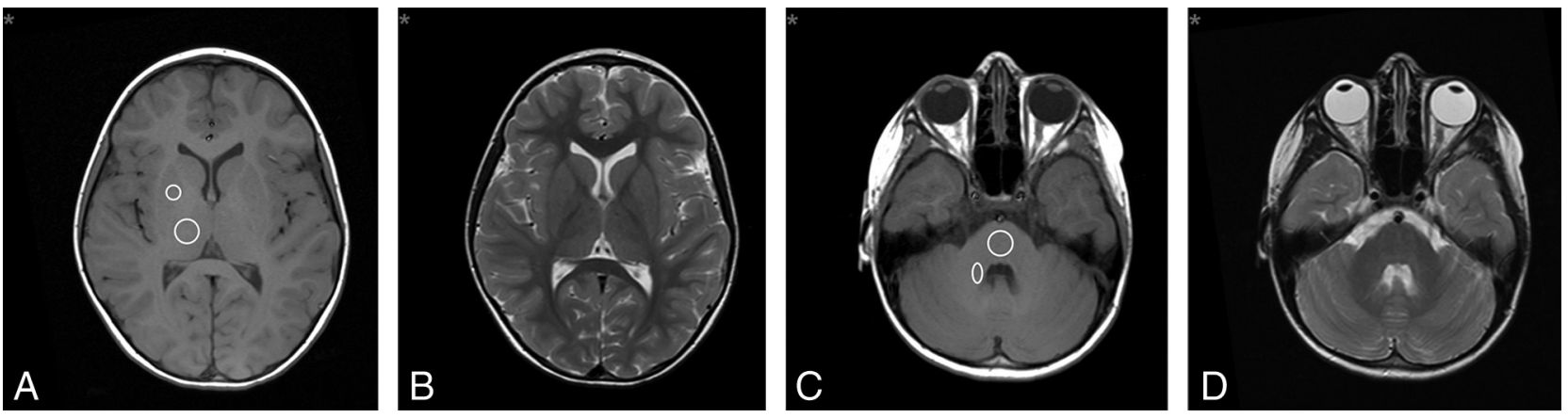

FIG 2. Oncologic female patient (7 years 2 months of age at her first visit) undergoing follow-up imaging for non-Hodgkin lymphoma in remission. Unenhanced T1- and T2-weighted transverse images of the DN-pons ( $A$ and $B)$ and GP-thalamus $(C$ and $D)$ after 14 injections of 0.05 $\mathrm{mmol} / \mathrm{kg}$ of gadobenate reveal no evidence of SI changes.

pentetate relative to GBCA-naïve control subjects (though no differences in GP-thalamus SI ratio were found) and in contrast to those of $\mathrm{Hu}$ et al, ${ }^{19}$ who found significantly higher $\mathrm{T} 1$ signal in the DN and GP of patients after serial exposure to gadopentetate than in the DN and GP of control subjects.

There are at least 2 possible reasons for the different findings.
First, our patient population was different. Whereas Flood et al ${ }^{18}$ and $\mathrm{Hu}$ et $\mathrm{al}^{19}$ evaluated patients who had undergone multiple brain examinations, our patient cohort comprised mainly oncologic patients with no known brain abnormalities. It is thus possible that the patients evaluated by Flood et al and $\mathrm{Hu}$ et al were more prone to brain Gd deposition due to a more compromised 
blood-brain barrier. On the other hand, studies have demonstrated T1-signal increases in the DN and GP even in the presence of a seemingly intact $\mathrm{BBB},{ }^{14,28}$ implying that the potential for T1-hyperintensity may be independent of the patient's clinical status and dependent solely on the amount of Gd administered. However, most of the Gd found deposited in the brain is actually in the perivascular space and has not passed the $\mathrm{BBB},{ }^{29,30}$ while Gd that does appear to have crossed an intact BBB is found primarily in the neural tissue interstitium rather than in neural cells. $^{14}$

Second, whereas gadobenate and gadopentetate are both ionic open-chain GBCAs, they differ fundamentally in that an aromatic substituent is present on the gadobenate molecule. On the one hand, this substituent influences the elimination profile of gadobenate, facilitating its excretion in part (typically up to $5 \%$ of the injected dose in subjects with normal renal function) via the hepatobiliary route. ${ }^{31}$ More pertinently, it also leads to markedly higher R1-relaxivity in vivo, ${ }^{22}$ which, in turn, leads to markedly increased SI enhancement on T1-weighted images for equivalent administered doses. A proven benefit of this higher relaxivity is that a lower gadobenate dose can be used to obtain diagnostically valid images. ${ }^{23,24}$ In our study, the mean accumulated dose across all patients was $9.8 \pm 8.33 \mathrm{~g}$, administered across a mean of $7.8 \pm$ 2.9 examinations (mean, $3.85 \pm 3.14 \mathrm{~mL}$ of MultiHance/examination, corresponding to $1.27 \pm 1.05 \mathrm{~g}$ of gadobenate/examination). This is considerably lower than the mean accumulated gadopentetate dose of $16.2 \pm 10.1 \mathrm{~g}$ across a mean of $5.9 \pm 2.7$ examinations (mean, 2.75 g gadopentetate/examination) given by Flood et $\mathrm{al}^{18}$ and would similarly be lower than that administered by $\mathrm{Hu}$ et $\mathrm{al},{ }^{19}$ given that they injected a standard dose of 0.1 $\mathrm{mmol} / \mathrm{kg}$ of gadopentetate/examination. At our institution, we routinely administer $0.05 \mathrm{mmol} / \mathrm{kg}$ of gadobenate for pediatric oncologic imaging.

An additional feature conferred by the aromatic substituent, which is invariably overlooked when simplistic comparisons are made between "linear" and macrocyclic GBCAs, ${ }^{4-10,32}$ is improved steric hindrance and thus increased kinetic inertia. An increased steric effect conferred by a bulky substituent potentially hinders unwrapping of the ligand around the gadolinium, thereby increasing molecular stability. ${ }^{33}$ Improved kinetic inertia due to an aromatic substituent has previously been demonstrated for gadofosveset. ${ }^{34}$ Unfortunately, accurate in vivo measurements of the kinetic stability of gadobenate are currently lacking, though its thermodynamic and conditional stability constants in vitro are the highest of all open-chain GBCAs and higher also than the macrocyclic agent gadobutrol. ${ }^{25}$ Further evidence of the inherent stability of gadobenate comes from the fact that this GBCA, unlike all other GBCAs except gadoterate meglumine (Dotarem; Guerbet, Aulnay-sous-Bois, France), does not contain any excess chelating agent in its formulation. ${ }^{25}$ Excess chelating agent is an indirect indicator of the potential of a GBCA to release Gd; that the gadobenate formulation does not contain excess chelate implies that it does not release Gd to the same extent as other GBCAs.

Our findings are in stark contrast to those of Weberling et al, ${ }^{10}$ who found significantly increased DN-pons and DN-CSF SI ratios after serial exposures of gadobenate to adults. However, several factors should be borne in mind when evaluating the results of Weberling et al. First, the patients evaluated were only required to have had a minimum of 5 consecutive gadobenate-enhanced MR imaging scans; each patient's first included scan was not necessarily the first scan the patient received, and prior scans with other GBCAs might have been performed. The likelihood that patients might have had prior MR imaging exams with other GBCAs is clearly a major confounding factor. Ramalho et $\mathrm{al}^{12}$ showed that significant $\mathrm{T} 1$ hyperintensity in deep brain nuclei occurred after the use of gadobenate in patients who had received prior administration of gadodiamide (Omniscan; GE Healthcare, Piscataway, New Jersey), but not in patients who had not previously received gadodiamide. An earlier report by Ramalho et $\mathrm{al}^{11}$ demonstrated significant SI increases in the DN and GP of patients who had received gadodiamide but not in patients who had received gadobenate. The lack of adequate patient screening by Weberling et $\mathrm{al}^{10}$ means that possible potentiating effects of prior exposure to other GBCAs could not be excluded.

Second, each patient evaluated by Weberling et al ${ }^{10}$ received a standardized volume of 15 or $20 \mathrm{~mL}$ of gadobenate per examination irrespective of body weight, resulting in a mean accumulated volume of $136.9 \pm 57.6 \mathrm{~mL}$ (ie, a mean accumulated dose of 45.72 $\mathrm{g}$ of gadobenate) between the first and last MR imaging examinations. Given that an approved gadobenate dose for all indications other than the liver, kidneys, urinary tract, and adrenal glands is $0.1 \mathrm{mmol} / \mathrm{kg}$ of body weight, ${ }^{26}$ which corresponds to $15 \mathrm{~mL}$ for a $75-\mathrm{kg}$ patient, any patient below $75 \mathrm{~kg}$ in weight would have received more than the approved dose (ie, more than the approved amount of Gd). Third, all except 1 of the patients evaluated by Weberling et al had brain metastases from melanoma, with many undergoing radiation therapy. These patients would certainly have had a more severely compromised $\mathrm{BBB}$, potentially allowing easier GBCA access to deep brain nuclei.

Weberling et al $^{10}$ ascribed their observed SI increases to Gd retention, speculating that their findings reflect the specific potential of gadobenate to release Gd. In drawing parallels with the postulated causative role of GBCAs in nephrogenic systemic fibrosis (NSF), they noted that gadobenate is classified as being of intermediate risk for NSF by the European Medicines Agency ${ }^{35}$; and in referring to 1 in vitro determination of kinetic stability conducted by a competitor to the manufacturer of gadobenate, ${ }^{36}$ they suggested that the potential for Gd release is similar for gadobenate and gadopentetate. Unfortunately, in vitro determinations of kinetic stability are inherently limited in that they cannot replicate normal physiologic conditions in vivo and cannot account for differing and unique routes of elimination among GBCAs. Although Weberling et $\mathrm{al}^{10}$ acknowledged that no unconfounded cases of NSF have been reported for gadobenate, ${ }^{37}$ they failed to point out that other relevant regulatory authorities, including the US Food and Drug Administration, classify gadobenate as having a low risk of NSF. ${ }^{38,39}$ In this regard, most (73\%) of the unconfounded published NSF cases were reported in the United States, ${ }^{40}$ and at the height of the NSF crisis (2006-2010), just 1 macrocyclic GBCA (gadoteridol, ProHance; Bracco Diagnostics) had FDA approval for commercial use. Gadobutrol (Gadavist; Bayer Healthcare) and gadoterate (Guerbet) were approved in 2011 and 2013, respectively. The other approved GBCAs besides gadobenate were gadodiamide (GE Healthcare), gadoversetamide 
(OptiMARK; Covidien), and gadopentetate (Bayer Healthcare), which were avoided and subsequently contraindicated in patients with severe renal impairment, ${ }^{38}$ leaving only gadobenate as an approved open-chain GBCA for routine applications in this population.

If, as is widely accepted, NSF occurs because of Gd release from the chelating molecule, ${ }^{35}$ then at least 1 unconfounded case might have been expected for gadobenate if, as postulated by Weberling et al, ${ }^{10} \mathrm{Gd}$ is released in vivo to an extent similar to that seen with gadopentetate. That no unconfounded cases have been reported despite exhaustive investigation ${ }^{41-43}$ suggests that Gd is not released from gadobenate to the same extent and that any observed T1 hyperintensity reflects retention of the intact molecule. Roberts et $\mathrm{al}^{44}$ recently reported high levels of Gd in the skin of a patient who underwent 61 enhanced brain examinations with a variety of GBCAs and that speciation analysis revealed intact gadobenate.

Further studies are required to determine whether T1 hyperintensity is seen in some patients after serial gadobenate exposure, and if so, whether this reflects accumulation of intact gadobenate or released Gd bound to macromolecules (eg, neuromelanin). In this regard, it is possible that Gd released from less stable GBCAs binds to macromolecules and that the observed $\mathrm{T} 1$ hyperintensity reflects elevated T1-signal due to slowing of the molecular tumbling rate of these Gd-macromolecule complexes. ${ }^{30}$ This hypothesis might explain why elevated T1 signal is observed with less stable GBCAs despite the very small Gd concentrations shown to be retained ${ }^{20}$ and, conceivably, why detectable high signal is less evident with more stable GBCAs if these are retained as fully intact molecules rather than as Gd-macromolecular complexes. ${ }^{45}$ Of note, however, is the study by Stojanov ${ }^{13}$ and a recent study in pediatric subjects by Rossi Espagnet et al. ${ }^{46}$ that demonstrate quantifiable T1 signal increases after multiple exposures to the macrocyclic GBCAs gadobutrol and gadoterate, respectively.

Also worthy of study is the possible differential impact of GBCA R1-relaxivity on T1 hyperintensity if GBCAs are retained as intact molecules; it is likely that retained GBCAs that have low R1-relaxivity may be less detectable than retained intact GBCAs that have higher R1-relaxivity. Finally, T1 signal increases are merely suggestive of Gd retention, and T1 hyperintensity might alternatively reflect various disease-related processes. ${ }^{47-49}$ While imaging studies can be considered, at best, an indirect secondlevel marker of Gd deposition, a true picture can only come from direct tissue analysis. In this regard, studies have demonstrated measurable Gd not only in the DN and GP but also in other brain areas and body organs. ${ }^{14,20,28}$ Most important, Murata et $\mathrm{al}^{20}$ have shown that deposition occurs with both linear and macrocyclic GBCAs and that it is up to 23 times higher in organs such as bone than in the brain.

Despite excellent interreader agreement regarding the reproducibility of SI measurements and despite the absence of significant differences in SI values between gadobenate-exposed and GBCA-naïve control subjects across any of the 4 evaluated brain regions, a significant difference in the GP-thalamus SI ratio was nevertheless still observed in 1 of the 5 blinded assessments. Although this can be explained by higher T1 signal in the thalamus of control subjects, it highlights the potential impact of even min- imal differences in SI measurements on study interpretation. This, in turn, points to the importance of multiple readers when performing quantitative evaluations and to the dangers of drawing conclusions based on evaluations performed by just 1 or 2 readers, particularly if such readers are not blinded to information regarding the images under evaluation. Accurate placing of ROIs for quantitative assessment is a highly subjective procedure, which is susceptible to considerable interreader variation.

Our study has some limitations. First, this was a single-center study. Second, because we assessed nonneurologic patients who had not previously undergone MR imaging of the brain, it was not possible to compare unenhanced T1-weighted images after multiple gadobenate administrations with baseline unenhanced images acquired before the first gadobenate administration. However, the lack of significant SI differences between gadobenate-exposed and GBCA-naïve control subjects suggests that no differences would have been seen. Third, we determined DNpons and GP-thalamus SI ratios despite Gd retention being observed in both the pons and thalamus. ${ }^{14,20}$ However, the T1 signal changes in these brain areas are much lower than in the $\mathrm{DN}$ and GP, and these ratios are commonly calculated parameters. ${ }^{1-4,8-13,16-18}$ Finally, we did not normalize the SI values of the DN and GP against the SI of the CSF to account for possible intraand intersequence signal-intensity differences, differences between MR units, and magnetic field inhomogeneity as described by McDonald et al. ${ }^{14}$ SI normalization might be appropriate for future studies.

\section{CONCLUSIONS}

Our study of 34 pediatric patients who received between 5 and 15 administrations of $0.05 \mathrm{mmol} / \mathrm{kg}$ of body weight gadobenate revealed no differences in T1 signal in the DN, GP, pons, and thalamus relative to measurements in 24 age- and weight-matched control subjects who had never been exposed to any GBCA. Likewise, no meaningful differences were seen in the DN-pons and GP-thalamus SI ratios. If T1 hyperintensity and Gd retention in deep brain nuclei occur in an exposure-dependent fashion, with greater $\mathrm{T} 1$ shortening observed following greater prior exposure to GBCAs, ${ }^{1}$ it would seem prudent to administer the lowest possible dose of a GBCA to achieve diagnostically valid studies, particularly when repeat MR imaging studies are required for follow-up or screening purposes. To this end, a recent intraindividual crossover study in which patients received $2 \mathrm{MR}$ imaging contrast agents in 2 otherwise identical MR imaging examinations has demonstrated similar diagnostic imaging performances for a half-dose $(0.05 \mathrm{mmol} / \mathrm{kg}$ of body weight $)$ of gadobenate relative to a full dose $(0.1 \mathrm{mmol} / \mathrm{kg}$ of body weight $)$ of the standard relaxivity macrocyclic GBCA, gadoterate, for morphologic imaging of brain tumors. ${ }^{23}$ Similarly, a prior study ${ }^{50}$ demonstrated significant superiority for a three-quarter dose $(0.075$ $\mathrm{mmol} / \mathrm{kg}$ of body weight) of gadobenate relative to a full dose ( 0.1 $\mathrm{mmol} / \mathrm{kg}$ of body weight) of gadoterate for cranial MR imaging. In both studies, similar or improved imaging performance was achieved with a lower total administered dose of gadolinium when gadobenate was used. We consider half-dose gadobenate safe and effective for diagnosis and routine follow-up of pediatric oncologic patients. 
Disclosures: Guenther K. Schneider-UNRELATED: Grants/Grants Pending: Bracco, Siemens, Bayer, Comments: research/clinical studies*; Payment for Lectures Including Service on Speakers Bureaus: Bracco, Siemens. Jonas Stroeder-UNRELATED: Payment for Lectures Including Service on Speakers Bureaus: Bracco, Comments: allowance for lecture given in June 2014. Giles Roditi-UNRELATED: Payment for Lectures Including Service on Speakers Bureaus: Bayer, Bracco, Comments: speaker honoraria once for each company for lecturing in educational courses. Cesare Colosimo-UNRELATED: Consultancy: Bracco, Bayer. Arno Buecker-UNRELATED: Payment for Lectures Including Service on Speakers Bureaus: Bracco. *Money paid to the institution.

\section{REFERENCES}

1. Kanda $\mathrm{T}$, Ishii $\mathrm{K}$, Kawaguchi $\mathrm{H}$, et al. High signal intensity in the dentate nucleus and globus pallidus on unenhanced T1-weighted MR images: relationship with increasing cumulative dose of a gadoliniumbased contrast material. Radiology 2014;270:834-41 CrossRef Medline

2. Errante Y, Cirimele V, Mallio CA, et al. Progressive increase of T1 signal intensity of the dentate nucleus on unenhanced magnetic resonance images is associated with cumulative doses of intravenously administered gadodiamide in patients with normal renal function, suggesting dechelation. Invest Radiol 2014;49:685-90 CrossRef Medline

3. Quattrocchi CC, Mallio CA, Errante Y, et al. Gadodiamide and dentate nucleus $\mathrm{T} 1$ hyperintensity in patients with meningioma evaluated by multiple follow-up contrast enhanced magnetic resonance examinations with no systemic interval therapy. Invest Radiol 2015; 50:470-72 CrossRef Medline

4. Radbruch A, Weberling LD, Kieslich PJ, et al. Gadolinium retention in the dentate nucleus and globus pallidus is dependent on the class of contrast agent. Radiology 2015;275:783-91 CrossRef Medline

5. Quattrocchi CC, Mallio CA, Errante Y, et al. High T1 signal intensity in dentate nucleus after multiple injections of linear gadolinium chelates. Radiology 2015;276:616-17 CrossRef Medline

6. Kanda T, Osawa M, Oba $\mathrm{H}$, et al. High signal intensity in dentate nucleus on unenhanced T1-weighted MR images: association with linear versus macrocyclic gadolinium chelate administration. $R a$ diology 2015;275:803-09 CrossRef Medline

7. Cao Y, Huang DQ, Shih G, et al. Signal change in the dentate nucleus on T1-weighted MR images after multiple administrations of gadopentetate dimeglumine versus gadobutrol. AJR Am J Roentgenol 2016;206:414-19 CrossRef Medline

8. Radbruch A, Weberling LD, Kieslich PJ, et al. Intraindividual analysis of signal intensity changes in the dentate nucleus after consecutive serial applications of linear and macrocyclic gadolinium-based contrast agents. Invest Radiol 2016;51:683-90 CrossRef Medline

9. Radbruch A, Weberling LD, Kieslich PJ, et al. High-signal intensity in the dentate nucleus and globus pallidus on unenhanced T1weighted images: evaluation of the macrocyclic gadolinium-based contrast agent gadobutrol. Invest Radiol 2015;50:805-10 CrossRef Medline

10. Weberling LD, Kieslich PJ, Kickingereder P, et al. Increased signal intensity in the dentate nucleus on unenhanced T1-weighted images after gadobenate dimeglumine administration. Invest Radiol 2015;50:743-48 CrossRef Medline

11. Ramalho J, Castillo M, AlObaidy M, et al. High signal intensity in globus pallidus and dentate nucleus on unenhanced T1-weighted MR images: evaluation of two linear gadolinium-based contrast agents. Radiology 2015;276:836-44 CrossRef Medline

12. Ramalho J, Semelka RC, AlObaidy M, et al. Signal intensity change on unenhanced T1-weighted images in dentate nucleus following gadobenate dimeglumine in patients with and without previous multiple administrations of gadodiamide. Eur Radiol 2016;26: 4080-88 CrossRef Medline

13. Stojanov DA, Aracki-Trenkic A, Vojinovic S, et al. Increasing signal intensity within the dentate nucleus and globus pallidus on unenhanced T1W magnetic resonance images in patients with relapsingremitting multiple sclerosis: correlation with cumulative dose of a macrocyclic gadolinium-based contrast agent, gadobutrol. Eur Radiol 2016;26:807-15 CrossRef Medline
14. McDonald RJ, McDonald JS, Kallmes DF, et al. Intracranial gadolinium deposition after contrast-enhanced MR imaging. Radiology 2015;275:772-82 CrossRef Medline

15. Miller $\mathrm{JH}, \mathrm{Hu} \mathrm{HH}$, Pokorney A, et al. MRI brain signal intensity changes of a child during the course of 35 gadolinium contrast examinations. Pediatrics 2015;136:e1637-40 CrossRef Medline

16. Roberts DR, Holden KR. Progressive increase of T1 signal intensity in the dentate nucleus and globus pallidus on unenhanced T1weighted MR images in the pediatric brain exposed to multiple doses of gadolinium contrast. Brain Dev 2016;38:331-36 CrossRef Medline

17. Roberts DR, Chatterjee AR, Yazdani M, et al. Pediatric patients demonstrate progressive $\mathrm{T} 1$-weighted hyperintensity in the dentate nucleus following multiple doses of gadolinium-based contrast agent. AJNR Am J Neuroradiol 2016;37:2340-47 CrossRef Medline

18. Flood TF, Stence NV, Maloney JA, et al. Pediatric brain: repeated exposure to linear gadolinium-based contrast material is associated with increased signal intensity at unenhanced T1-weighted MR imaging. Radiology 2017;282:222-28 CrossRef Medline

19. $\mathrm{Hu} \mathrm{HH}$, Pokorney A, Towbin $\mathrm{RB}$, et al. Increased signal intensities in the dentate nucleus and globus pallidus on unenhanced T1-weighted images: evidence in children undergoing multiple gadolinium MRI exams. Pediatr Radiol 2016;46:1590-98 CrossRef Medline

20. Murata N, Gonzalez-Cuyar LF, Murata K, et al. Macrocyclic and other non-group 1 gadolinium contrast agents deposit low levels of gadolinium in brain and bone tissue: preliminary results from 9 patients with normal renal function. Invest Radiol 2016;51:447-53 CrossRef Medline

21. Laurent S, Elst LV, Muller RN. Comparative study of the physicochemical properties of six clinical low molecular weight gadolinium contrast agents. Contrast Media Mol Imaging 2006;1:128-37 CrossRef Medline

22. Shen Y, Goerner FL, Snyder C, et al. T1 relaxivities of gadoliniumbased magnetic resonance contrast agents in human whole blood at 1.5, 3, and 7 T. Invest Radiol 2015;50:330-38 CrossRef Medline

23. Vaneckova M, Herman M, Smith MP, et al. The benefits of high relaxivity for brain tumor imaging: results of a multicenter intraindividual crossover comparison of gadobenate dimeglumine with gadoterate meglumine (The BENEFIT Study). AJNR Am J Neuroradiol 2015;36:1589-98 CrossRef Medline

24. Morana G, Grazioli L, Kirchin MA, et al. Solid hypervascular liver lesions: accurate identification of true benign lesions on enhanced dynamic and hepatobiliary phase magnetic resonance imaging after gadobenate dimeglumine administration. Invest Radiol 2011;46: 225-39 CrossRef Medline

25. van der Molen AJ. Nephrogenic systemic fibrosis and the role of gadolinium contrast media. J Med Imaging Radiat Oncol 2008;52: 339-50 CrossRef Medline

26. MultiHance Summary of Product Characteristics. Updated September 29, 2016. https://www.medicines.org.uk/emc/medicine/6132. Accessed May 26, 2017

27. American College of Radiology. ACR Manual on Contrast Media. Version 10.2; 2016. http://www.acr.org/quality-safety/resources/contrastmanual. Accessed August 29, 2016

28. Kanda T, Fukusato T, Matsuda M, et al. Gadolinium-based contrast agent accumulates in the brain even in subjects without severe renal dysfunction: evaluation of autopsy brain specimens with inductively coupled plasma mass spectroscopy. Radiology 2015;276: 228-32 CrossRef Medline

29. Naganawa S, Nakane T, Kawai H, et al. Gd-based contrast enhancement of the perivascular spaces in the basal ganglia. Magn Reson Med Sci 2017;16:61-65

30. Hoggard N, Roditi GH. T1 hyperintensity on brain imaging subsequent to gadolinium-based contrast agent administration: what do we know about intracranial gadolinium deposition? $\mathrm{Br} \mathrm{J}$ Radiol 2017;90:20160590 CrossRef Medline

31. Spinazzi A, Lorusso V, Pirovano G, et al. Safety, tolerance, biodistribution, and MR imaging enhancement of the liver with gadobenate 
dimeglumine: results of clinical pharmacologic and pilot imaging studies in nonpatient and patient volunteers. Acad Radiol 1999;6: 282-91 CrossRef Medline

32. Malayeri AA, Brooks KM, Bryant LH, et al. National Institutes of Health perspective on reports of gadolinium deposition in the brain. J Am Coll Radiol 2016;13:237-41 CrossRef Medline

33. Idée JM, Port M, Robic C, et al. Role of thermodynamic and kinetic parameters in gadolinium chelate stability. J Magn Reson Imaging. 2009;30:1249-58 CrossRef Medline

34. Caravan P, Comuzzi C, Crooks W, et al. Thermodynamic stability and kinetic inertness of MS-325, a new blood pool agent for magnetic resonance imaging. Inorg Chem 2001;40:2170-76 CrossRef Medline

35. Thomsen HS, Morcos SK, Almén T, et al; ESUR Contrast Medium Safety Committee. Nephrogenic systemic fibrosis and gadoliniumbased contrast media: updated ESUR Contrast Medium Safety Committee guidelines. Eur Radiol 2013;23:307-18 CrossRef Medline

36. Frenzel T, Lengsfeld P, Schirmer H, et al. Stability of gadoliniumbased magnetic resonance imaging contrast agents in human serum at 37 degrees C. Invest Radiol 2008;43:817-28 CrossRef Medline

37. Heverhagen JT, Krombach GA, Gizewski E. Application of extracellular gadolinium-based MRI contrast agents and the risk of nephrogenic systemic fibrosis. Rofo 2014;186:661-69 CrossRef Medline

38. Yang L, Krefting I, Gorovets A, et al. Nephrogenic systemic fibrosis and class labeling of gadolinium-based contrast agents by the Food and Drug Administration. Radiology 2012;265:248-53 CrossRef Medline

39. Guideline on the use of gadolinium-containing MRI contrast agents in patients with renal impairment. V2. https://www.ranzcr.com/ search/gadolinium-containing-mri-contrast-agents-guidelines. Accessed May 26, 2017

40. Spinazzi A. MRI contrast agents and nephrogenic systemic fibrosis. In: Shellock FG, Crues JV, Karacozoff AM, eds. MRI Bioeffects, Safety, and Patient Management. Los Angeles: Biomedical Research Publishing Group; 2014:chap 11:256-81

41. Nandwana SB, Moreno CC, Osipow MT, et al. Gadobenate dimeglumine administration and nephrogenic systemic fibrosis: is there a real risk in patients with impaired renal function? Radiology 2015; 276:741-47 CrossRef Medline

42. Soulez G, Bloomgarden DC, Rofsky NM, et al. Prospective cohort study of nephrogenic systemic fibrosis in patients with stage 3-5 chronic kidney disease undergoing MRI with injected gadobenate dimeglumine or gadoteridol. AJR Am J Roentgenol 2015;205:469-78 CrossRef Medline

43. Bruce R, Wentland AL, Haemel AK, et al. Incidence of nephrogenic systemic fibrosis using gadobenate dimeglumine in 1423 patients with renal insufficiency compared with gadodiamide. Invest Radiol 2016;51:701-05 CrossRef Medline

44. Roberts DR, Lindhorst SM, Welsh CT, et al. High levels of gadolinium deposition in the skin of a patient with normal renal function. Invest Radiol 2016;51:280 - 89 CrossRef Medline

45. Jost G, Lenhard DC, Sieber MA, et al. Signal increase on unenhanced T1-weighted images in the rat brain after repeated, extended doses of gadolinium-based contrast agents: comparison of linear and macrocyclic agents. Invest Radiol 2016;51:83-89

46. Rossi Espagnet MC, Bernardi B, Pasquini L, Figà-Talamanca L, et al. Signal intensity at unenhanced $\mathrm{T} 1$-weighted magnetic resonance in the globus pallidus and dentate nucleus after serial administrations of a macrocyclic gadolinium-based contrast agent in children. Pediatr Radiol 2017 May 19. [Epub ahead of print] CrossRef

47. Prosch $\mathrm{H}$, Grois N, Wnorowski M, et al. Long-term MR imaging course of neurodegenerative Langerhans cell histiocytosis. AJNR Am J Neuroradiol 2007;28:1022-28 CrossRef Medline

48. Maeda H, Sato M, Yoshikawa A, et al. Brain MR imaging in patients with hepatic cirrhosis: relationship between high intensity signal in basal ganglia on T1-weighted images and elemental concentrations in brain. Neuroradiology 1997;39:546-50 CrossRef Medline

49. Mochizuki H, Kamakura K, Masaki T, et al. Atypical MRI features of Wilson's disease: high signal in globus pallidus on T1-weighted images. Neuroradiology 1997;39:171-74 CrossRef Medline

50. Khouri Chalouhi K, Papini GD, Bandirali M, et al. Less is better? Intraindividual and interindividual comparison between 0.075 $\mathrm{mmol} / \mathrm{kg}$ of gadobenate dimeglumine and $0.1 \mathrm{mmol} / \mathrm{kg}$ of gadoterate meglumine for cranial MRI. Eur J Radiol 2014;83:1245-49 CrossRef Medline 